\title{
Advanced liver disease outcomes after hepatitis C eradication by human immunodeficiency virus infection in PITER cohort
}

\author{
Maria Giovanna Quaranta ${ }^{1}$ Luigina Ferrigno ${ }^{1} \cdot$ Monica Monti $^{2} \cdot$ Roberto Filomia $^{3}$ - Elisa Biliotti ${ }^{4} \cdot$ Andrea lannone $^{5}$. \\ Guglielmo Migliorino $^{6} \cdot$ Barbara Coco $^{7}$. Filomena Morisco ${ }^{8} \cdot$ Maria Vinci $^{9} \cdot$ Roberta D'Ambrosio $^{10}$. \\ Liliana Chemello ${ }^{11}$. Marco Massari ${ }^{12}$. Donatella leluzzi ${ }^{13}$. Francesco Paolo Russo $^{14}$. Pierluigi Blanc ${ }^{15}$. \\ Gabriella Verucchi ${ }^{16}$. Massimo Puoti ${ }^{17}$. Maria Grazia Rumi ${ }^{18}$. Francesco Barbaro ${ }^{19}$. Teresa Antonia Santantonio ${ }^{20}$. \\ Alessandro Federico ${ }^{21}$. Luchino Chessa ${ }^{22}$ - Ivan Gentile ${ }^{23}$. Massimo Zuin ${ }^{24}$. Giustino Parruti ${ }^{25}$. Giulia Morsica ${ }^{26}$. \\ Loreta A. Kondili ${ }^{1}$. on behalf of PITER Collaborating Group
}

Received: 18 December 2019 / Accepted: 18 March 2020 / Published online: 11 April 2020

(c) The Author(s) 2020

\begin{abstract}
Background Liver disease progression after Hepatitis C Virus (HCV) eradication following direct-acting antiviral (DAA) treatment in the real-life setting according to Human Immunodeficiency Virus (HIV) coinfection was evaluated.

Methods Patients consecutively enrolled in PITER between April 2014 and June 2019 and with at least 12-weeks follow-up following treatment were analysed. Cox regression analysis were used to evaluate HIV coinfection and factors independently associated with liver disease outcomes following viral eradication in DAA treated patients with pre-treatment liver cirrhosis. Results $93 \mathrm{HIV} / \mathrm{HCV}$ coinfected and $1109 \mathrm{HCV}$ monoinfected patients were evaluated during a median follow-up of 26.7 (range 6-44.6) and 24.6 (range 6.8-47.3) months, respectively. No difference in the cumulative HCC incidence and hepatic decompensation was observed between coinfected and monoinfected patients. Age (Hazard Ratio [HR] $=1.08 ; 95 \%$ CI 1.04-1.13), male sex ( $\mathrm{HR}=2.76$; 95\% CI 1.28-5.96), lower albumin levels ( $\mathrm{HR}=3.94 ; 95 \%$ CI 1.81-8.58), genotype 3 $(\mathrm{HR}=5.05 ; 95 \% \mathrm{CI} 1.75-14.57)$ and serum anti-HBc positivity $(\mathrm{HR}=1.99,95 \% \mathrm{CI} 1.01-3.95)$ were independently associated with $\mathrm{HCC}$ incidence. Older age $(\mathrm{HR}=1.03$; $95 \% \mathrm{CI} 1.00-1.07)$, male sex $(\mathrm{HR}=2.13$; 95\% CI 1.06-4.26) and lower albumin levels ( $\mathrm{HR}=3.75 ; 95 \%$ CI 1.89-7.46) were independently associated with the appearance of a decompensating event after viral eradication.

Conclusion Different demographic, clinical and genotype distribution between HIV coinfected vs those monoinfected, was observed in a representative cohort of HCV infected patients in Italy. Once liver cirrhosis is established the disease progression is decreased, but still persists regardless of viral eradication in both coinfected and monoinfected patients. In patients with cirrhosis, HIV coinfection was not associated with a higher probability of liver complications, after viral eradication.
\end{abstract}

Keywords Hepatitis C virus · Human immunodeficiency virus · Coinfection · Real-life cohort · Direct-acting antivirals · Advanced liver disease $\cdot$ Sustained virological response $\cdot$ Clinical outcomes · Cirrhosis · Hepatocellular carcinoma $\cdot$ Viral eradication

\section{Introduction}

Worldwide, approximately 2.3 million people are co-infected with Human Immunodeficiency Virus (HIV) and Hepatitis $\mathrm{C}$ Virus (HCV), giving rise to a global co-infection prevalence in HIV infected individuals of 6.2\% [1]. It is known

Loreta A. Kondili

loreta.kondili@iss.it

Extended author information available on the last page of the article that HIV accelerates the course of HCV-related chronic liver disease. Patients have a faster progression of liver fibrosis, a higher risk of developing cirrhosis, liver decompensation, hepatocellular carcinoma (HCC), and liver-related mortality and this effect is not completely reverted by antiretroviral therapy [2-4].

The development of direct-acting antivirals (DAAs) has revolutionized the treatment of $\mathrm{HCV}$, with very high cure rates $[5,6]$. The achievement of sustained virological response 12 weeks after completion of treatment (SVR12) 
has been associated with improved liver function, decreased clinical complications and all-cause mortality [7-10]. With regard to HIV coinfection, inferior treatment response in patients with HIV is no longer a concern and regimens proven efficacious in HCV monoinfection are widely applicable to patients with HIV [11]. However, little is known about whether HIV coinfection modifies outcomes of HCVrelated liver disease after achieving SVR.

The aim of the present analysis was to evaluate the sociodemographic and clinical profile of HIV/HCV coinfected vs HCV monoinfected patients in a real-life patients' cohort with the final goal to prospectively evaluate the clinical impact of DAA treatment in patients with progressive/severe liver disease according to HIV coinfection status.

\section{Methods}

\section{Study design and patients}

The study population consisted of patients with chronic HCV infection consecutively enrolled in Piattaforma Italiana per lo studio della Terapia delle epatiti ViRali (PITER) between April 2014 and June 2019, who were not receiving HCV treatment at the time of inclusion, and could be considered representative of the $\mathrm{HCV}$ chronic infected population in care in Italy [12].

For the present study, we included all consecutively enrolled HCV-infected patients (any stage, any genotype, including $\mathrm{HIV} / \mathrm{HCV}$ coinfected patients and HCV monoinfected patients with known HIV negative status).

For each patient, baseline demographic, clinical and laboratory characteristics were recorded during the patient's visit at treatment start. Further data were recorded during the follow-up after completion of treatment.

Fibrosis stage was defined based on liver transient elastography data, which were considered as validated if each patient had at least 10 valid stiffness measurements, with a success rate of at least $80 \%$, an interquartile range of less than $30 \%$ of the median stiffness score, and a body mass index (BMI) of $<30 \mathrm{~kg} / \mathrm{m}^{2}$ [13]. Liver cirrhosis was defined when the stiffness score was equal to or higher than $12.5 \mathrm{kPa}$ or according to biochemical and instrumental data of portal hypertension [13].

Decompensated cirrhosis was diagnosed according to the presence or appearance of ascites and/or portal hypertensive gastrointestinal bleeding and/or hepatic encephalopathy. Ascites was detected by ultrasound as routine evaluation in each outpatient or inpatient with cirrhosis.

\section{Outcome variables}

The study outcomes following HCV eradication were evaluated in DAA treated patients with pre-treatment diagnosis of liver cirrhosis. Patients with a history of decompensated cirrhosis or liver transplantation prior to treatment were excluded from this analysis considering their different pathogenesis compared to patients with chronic hepatitis and liver cirrhosis without complications. Clinical outcomes evaluated following the SVR12 included the appearance of incident HCC and the first occurrence of a decompensating event.

\section{Statistical analysis}

Patient's main baseline characteristics were reported as median and range or as proportions ( $\mathrm{N}$ and \%) for continuous and categorical variables, respectively. The Mann-Whitney $U$ test was used for continuous variables to assess differences between distribution, and the Chisquared test was used for comparisons of proportions. A $p$ value of $<0.05$ was considered statistically significant. De novo HCC and decompensating event occurrences in $\mathrm{HCV}$ monoinfected and HIV/HCV coinfected groups were examined using Kaplan-Meier survival analyses. The logrank test was used to identify significant differences in survival between groups.

Variables independently associated to HCC incidence and the appearance of a decompensating event following viral eradication were evaluated by Cox proportional hazard models adopting a forward stepwise selection, adding terms with $p \leq 0.1$ and removing those with $p \geq 0.2$.

To confirm the main results of the analyses, the propensity score was estimated using a nonparsimonious logistic regression model with the HIV infection as the dependent variable and all measured potential confounders as covariates. The following variables at baseline have been included: age, sex, BMI, alcohol, ALT, AST, platelets, albumin, bilirubin, INR, genotype, diabetes, anti-HBc, HBsAg, previous Interferon, HCC. Relationship between each outcome and HIV adjusted by propensity score was evaluated by multiple Cox regression analyses.

All analyses were performed using the STATA/SE 15.1 statistical package (StataCorp LP, College Station, TX, USA). 


\section{Results}

\section{Baseline clinical characteristics}

Data from $244 \mathrm{HIV} / \mathrm{HCV}$ coinfected patients $(74.6 \%$ males) and $2870 \mathrm{HCV}$ monoinfected patients with known HIV negative status (54.1\% males), treated with DAA and with a median follow-up since enrollment of 38.9 months (range 4.1-60.8), were included. The baseline demographic, clinical and biochemical characteristics are shown in Table 1.

The median age of the coinfected and monoinfected patients was 52 years (range 32-77) and 61 years (range $20-86)$, respectively $(p<0.001)$.

Compared to monoinfected patients, coinfected patients had a significant lower BMI [66.4\% of coinfected patients were in the normal BMI group, while monoinfected patients were equally distributed between the normal $(47.1 \%)$ and the overweight group (defined as having a BMI of $\geq 25$ and $\left.\left.<30 \mathrm{~kg} / \mathrm{m}^{2}\right)(40.4 \%) ; p<0.001\right]$.

Genotype 1a and 3 were prevalent in coinfected patients ( $n=80,32.8 \%$ and $n=65,26.6 \%$, respectively), whereas about half of the monoinfected patients $(n=1438,50.1 \%)$ were infected by HCV genotype $1 \mathrm{~b}(p<0.001)$.

Serum anti-HBc was detected in $98(40.2 \%)$ coinfected and in $591(20.6 \%)$ monoinfected patients $(p<0.001)$. No difference was found in HBsAg positivity between coinfected and monoinfected patients $(2.1 \%$ vs $1.2 \%, p>0.05)$.

There were no significant differences among coinfected and monoinfected patients for baseline alanine transaminase (ALT), aspartate transaminase (AST), platelet count, serum albumin, bilirubin and international normalized ratio (INR) value.

Overall, $101(49.5 \%)$ coinfected patients and 1164 (45.5\%) monoinfected patients were classified in the F4/ cirrhosis stage. A decompensating event occurred prior to treatment in $20(9.8 \%)$ and in $162(6.3 \%)$ coinfected and monoinfected patients, respectively $(p>0.05)$. No differences in the prevalence of liver transplantation, among coinfected and monoinfected patients, were observed prior to antiviral treatment.

\section{Clinical outcomes following SVR12 in patients with liver cirrhosis}

The post-treatment liver disease outcomes, were evaluated in DAA treated patients with pre-treatment diagnosis of liver cirrhosis who achieved SVR12. Patients with a history of decompensated cirrhosis or liver transplantation prior to treatment were excluded by this analysis as reported in the methods section.
Similar rates of SVR12 were observed in coinfected (94.9\%) and monoinfected (94.8\%) patients with liver cirrhosis. Coinfected and monoinfected patients were evaluated during a median follow-up of 26.7 (range 6-44.6) and 24.6 (range 6.8-47.3) months after viral eradication, respectively. Baseline characteristics of these patients are summarized in Table 2.

Coinfected patients were observed to have a significantly younger age (median age of 52 vs 64 years, $p<0.001$ ) and increased liver disease severity in terms of Child-Pugh (C-P) class distribution (C-P class A: $83.3 \%$ vs $96.6 \%$; C-P class B: $16.7 \%$ vs $3.4 \%$ ), compared to HCV monoinfected patients $(p<0.001)$. Prior to antiviral treatment, no difference in the prevalence of HCC, among coinfected and monoinfected patients, was observed. Serum anti-HBc was detected in $42(45.2 \%)$ coinfected and in $248(22.4 \%)$ monoinfected patients $(p<0.001)$. No difference was found in HBsAg positivity between coinfected and monoinfected patients (3.2\% vs $1.3 \%, \mathrm{p}>0.05)$.

Overall, no significant differences were observed among coinfected and monoinfected patients for the different outcomes evaluated. Following viral eradication, similar cumulative incidence of HCC was observed in coinfected (in 2 patients $=2.2 \%$ ) and monoinfected patients (in 40 patients $=3.9 \%)(p>0.05)$. The occurrence of a decompensating event was observed in 4 (4.3\%) of coinfected patients and in $53(4.8 \%)$ of monoinfected patients. No differences on the incidence of HCC and of decompensating event after viral eradication were observed between the two groups, as shown by Kaplan-Meier curves (log-rank test $p=0.390$ and $p=0.837$, respectively) (Figs. 1 and 2).

\section{Predictors of clinical outcomes following SVR12}

Following Cox regression analysis, it was observed that age (increasing years; $\mathrm{HR}=1.08$; 95\% CI 1.04-1.13), male sex $(\mathrm{HR}=2.76$; 95\% CI 1.28-5.96), lower baseline albumin levels $(\mathrm{HR}=3.9495 \%$; CI 1.81-8.58), genotype $3(\mathrm{HR}=5.05$; 95\% CI 1.75-14.57) and serum anti-HBc positivity $(\mathrm{HR}=1.99 ; 95 \%$ CI 1.01-3.95) were factors independently associated with de novo HCC occurrence after successful DAA treatment (Table 3).

Factors independently associated with the appearance of a decompensating event included age (increasing years; $\mathrm{HR}=1.03 ; 95 \%$ CI $1.00-1.07)$, male sex $(\mathrm{HR}=2.13 ; 95 \%$ CI 1.06-4.26) and lower baseline albumin levels $(\mathrm{HR}=3.75$ 95\%; CI 1.89-7.46) (Table 4).

As shown in Tables 3 and 4, HIV coinfection was not associated with a higher probability of developing liver complications (HCC or the appearance of a decompensating event). In addition, because observational studies do not provide randomization, the propensity score method 
Table 1 Patients' main baseline characteristics

\begin{tabular}{|c|c|c|c|c|}
\hline Quantitative variables & $\begin{array}{l}\text { All patients }\left(N=3114^{*}\right) \\
\text { Median (Range) }\end{array}$ & $\begin{array}{l}\text { HIV/HCV coinfected }(N=244 *) \\
\text { Median (Range) }\end{array}$ & $\begin{array}{l}\text { HCV monoinfected }(N=2870 *) \\
\text { Median (Range) }\end{array}$ & $p^{* *}$ \\
\hline Age (years) & $59(20-86)$ & $52(32-77)$ & $61(20-86)$ & $<0.001$ \\
\hline ALT (IU/L) & $61.0(7.0-969.0)$ & $56.0(10.0-301.0)$ & $61.0(7.0-969.0)$ & 0.1439 \\
\hline AST (IU/L) & $54.0(11.0-652.0)$ & $53.0(15.0-371.0)$ & $55.0(11.0-652.0)$ & 0.5986 \\
\hline Platelets $/ \mu \mathrm{L}$ & $160000(15,000-752,000)$ & $153,500(29,000-540,000)$ & $160,000(15,000-752,000)$ & 0.0569 \\
\hline Albumin (g/dL) & $4.0(0.4-7.5)$ & $4.0(0.4-5.1)$ & $4.0(0.5-7.5)$ & 0.8547 \\
\hline Bilirubin (mg/dL) & $0.8(0.1-70.0)$ & $0.7(0.1-58.0)$ & $0.8(0.1-70.0)$ & 0.4100 \\
\hline INR & $1.0(0.5-9.0)$ & $1.0(0.7-1.5)$ & $1.0(0.5-9.0)$ & 0.1863 \\
\hline Categorical variables & $N .(\%)$ & $N .(\%)$ & $N .(\%)$ & $p^{* * *}$ \\
\hline \multicolumn{5}{|l|}{ Sex } \\
\hline Male & $1736(55.8)$ & $182(74.6)$ & $1554(54.2)$ & \multirow[t]{2}{*}{$<0.001$} \\
\hline Female & $1378(44.3)$ & $62(25.4)$ & $1316(45.9)$ & \\
\hline \multicolumn{5}{|l|}{ BMI } \\
\hline Underweight & $71(2.3)$ & $13(5.3)$ & $58(2.0)$ & \multirow[t]{4}{*}{$<0.001$} \\
\hline Normal & 1513 (48.6) & $162(66.4)$ & $1351(47.1)$ & \\
\hline Overweight & $1216(39.1)$ & $58(23.8)$ & $1158(40.4)$ & \\
\hline Obese & $313(10.1)$ & $11(4.5)$ & $302(10.5)$ & \\
\hline \multicolumn{5}{|l|}{ Alcohol use } \\
\hline Never & $1978(65.2)$ & $104(47.1)$ & $1874(66.6)$ & \multirow[t]{3}{*}{$<0.001$} \\
\hline Current & $441(14.5)$ & $73(33.0)$ & $368(13.1)$ & \\
\hline Past & $615(20.3)$ & $44(19.9)$ & $571(20.3)$ & \\
\hline \multicolumn{5}{|l|}{ Genotype } \\
\hline 1 (Non subtyped) & $108(3.5)$ & $17(7.0)$ & $91(3.2)$ & \multirow[t]{6}{*}{$<0.001$} \\
\hline $1 \mathrm{a}$ & $472(15.2)$ & $80(32.8)$ & $392(13.7)$ & \\
\hline $1 b$ & $1467(47.1)$ & $29(11.9)$ & $1438(50.1)$ & \\
\hline 2 & 478 (15.4) & $11(4.5)$ & $467(16.3)$ & \\
\hline 3 & $352(11.3)$ & $65(26.6)$ & $287(10.0)$ & \\
\hline $4-5$ & 237 (7.6) & $42(17.2)$ & $195(6.8)$ & \\
\hline \multicolumn{5}{|l|}{ Diabetes } \\
\hline Yes & $439(14.1)$ & $26(10.7)$ & $413(14.4)$ & \multirow[t]{2}{*}{0.108} \\
\hline No & $2675(85.9)$ & $218(89.3)$ & 2457 (85.6) & \\
\hline \multicolumn{5}{|l|}{ Anti-HBc+ } \\
\hline Yes & $689(22.1)$ & $98(40.2)$ & $591(20.6)$ & \multirow[t]{2}{*}{$<0.001$} \\
\hline No & 2425 (77.9) & $146(59.8)$ & $2279(79.4)$ & \\
\hline \multicolumn{5}{|l|}{ HBsAg+ } \\
\hline Yes & $39(1.3)$ & $5(2.1)$ & $34(1.2)$ & \multirow[t]{2}{*}{0.244} \\
\hline No & $3075(98.8)$ & $239(98.0)$ & $2836(98.8)$ & \\
\hline \multicolumn{5}{|l|}{ Previous interferon } \\
\hline Yes & $916(29.4)$ & $55(22.5)$ & $861(30.0)$ & \multirow[t]{2}{*}{0.014} \\
\hline No & 2198 (70.6) & $189(77.5)$ & $2009(70.0)$ & \\
\hline \multicolumn{5}{|l|}{ Liver disease stage } \\
\hline F0-F3 & $1246(45.1)$ & $81(39.7)$ & 1165 (45.6) & \multirow[t]{4}{*}{0.057} \\
\hline F4-cirrhosis & $1265(45.8)$ & $101(49.5)$ & $1164(45.5)$ & \\
\hline Decompensated cirrhosis & $182(6.6)$ & $20(9.8)$ & $162(6.3)$ & \\
\hline Liver transplantation & $68(2.5)$ & $2(1.0)$ & $66(2.6)$ & \\
\hline
\end{tabular}

$p$ values $<0.05$ are reported in bold

*For some variables inconsistencies are due to missing values

** $p$ value Mann-Whitney rank-sum test.

*** $p$ value Chi-squared test 
Table 2 Baseline characteristics of cirrhotic patients successfully treated with DAA

\begin{tabular}{|c|c|c|c|}
\hline Quantitative variables & $\begin{array}{l}\mathrm{HIV} / \mathrm{HCV} \text { coinfected ( } \mathrm{N}=93 *-\mathrm{SVR} 94.9 \%) \\
\text { Median (Range) }\end{array}$ & $\begin{array}{l}\text { HCV monoinfected ( } \mathrm{N}=1109 * \text { - SVR } 94.8 \%) \\
\text { Median (Range) }\end{array}$ & $p^{* *}$ \\
\hline FU time since EOT (months) & $26.7(6.0-44.6)$ & $24.6(6.8-47.3)$ & 0.7595 \\
\hline Age (years) & $52(36-77)$ & $64(23-86)$ & $<0.001$ \\
\hline $\operatorname{ALT}(\mathrm{IU} / \mathrm{L})$ & $65.5(11.0-268.0)$ & $76.5(10.0-797.0)$ & 0.0365 \\
\hline AST (IU/L) & $63.5(23.0-371.0)$ & $71.0(13.0-652.0)$ & 0.3184 \\
\hline Platelets $/ \mu \mathrm{L}$ & $115,000(29,000-262,000)$ & $121,000(15,000-510,000)$ & 0.2817 \\
\hline Albumin $(\mathrm{g} / \mathrm{dL})$ & $4.0(3.0-5.1)$ & $4.0(2.1-7.3)$ & 0.9712 \\
\hline Bilirubin (mg/dL) & $0.8(0.3-7.0)$ & $0.9(0.2-15.5)$ & 0.6845 \\
\hline INR & $1.1(0.9-1.5)$ & $1.1(0.6-5.0)$ & 0.6735 \\
\hline Categorical variables & $N .(\%)$ & N. $(\%)$ & $p^{* * *}$ \\
\hline \multicolumn{4}{|l|}{ Sex } \\
\hline Male & 74 (79.6) & $642(57.9)$ & $<0.001$ \\
\hline Female & $19(20.4)$ & $467(42.1)$ & \\
\hline \multicolumn{4}{|l|}{ BMI } \\
\hline Underweight & $5(5.4)$ & $11(1.0)$ & $<0.001$ \\
\hline Normal & $59(63.4)$ & $463(41.8)$ & \\
\hline Overweight & $22(23.7)$ & $489(44.1)$ & \\
\hline Obese & $7(7.5)$ & $145(13.1)$ & \\
\hline Alcohol use & & & $<0.001$ \\
\hline Never & $43(51.2)$ & $716(65.9)$ & \\
\hline Current & $25(29.8)$ & $109(10.0)$ & \\
\hline Past & $16(19.1)$ & $261(24.0)$ & \\
\hline \multicolumn{4}{|l|}{ Genotype } \\
\hline 1 (Non subtyped) & $5(5.4)$ & $31(2.8)$ & $<0.001$ \\
\hline 1a & $29(31.2)$ & $157(14.2)$ & \\
\hline $1 b$ & $13(14.0)$ & $592(53.4)$ & \\
\hline 2 & $4(4.3)$ & $156(14.1)$ & \\
\hline 3 & 25 (26.9) & $104(9.4)$ & \\
\hline $4-5$ & $17(18.3)$ & $69(6.2)$ & \\
\hline \multicolumn{4}{|l|}{ Diabetes } \\
\hline Yes & $11(11.8)$ & $220(19.8)$ & 0.060 \\
\hline No & $82(88.2)$ & $889(80.2)$ & \\
\hline \multicolumn{4}{|l|}{ Anti-HBc+ } \\
\hline Yes & $42(45.2)$ & $248(22.4)$ & $<0.001$ \\
\hline No & $51(54.8)$ & 861 (77.6) & \\
\hline \multicolumn{4}{|l|}{ HBsAg+ } \\
\hline Yes & $3(3.2)$ & $14(1.3)$ & 0.124 \\
\hline No & $90(96.8)$ & 1095 (98.7) & \\
\hline \multicolumn{4}{|l|}{ Previous interferon } \\
\hline Yes & $26(28.0)$ & $375(33.8)$ & 0.250 \\
\hline No & $67(72.0)$ & $734(66.2)$ & \\
\hline \multicolumn{4}{|l|}{$\mathrm{HCC}$} \\
\hline Yes & $1(1.1)$ & $55(5.0)$ & 0.088 \\
\hline No & $92(98.9)$ & $1054(95.0)$ & \\
\hline \multicolumn{4}{|l|}{ Child-pugh class } \\
\hline A & $50(83.3)$ & 940 (96.6) & $<0.001$ \\
\hline B & $10(16.7)$ & $33(3.4)$ & \\
\hline
\end{tabular}

$p$ values $<0.05$ are reported in bold

* For some variables inconsistencies are due to missing values

** $p$ value Mann-Whitney rank-sum test

$* * * p$ value Chi-squares test 


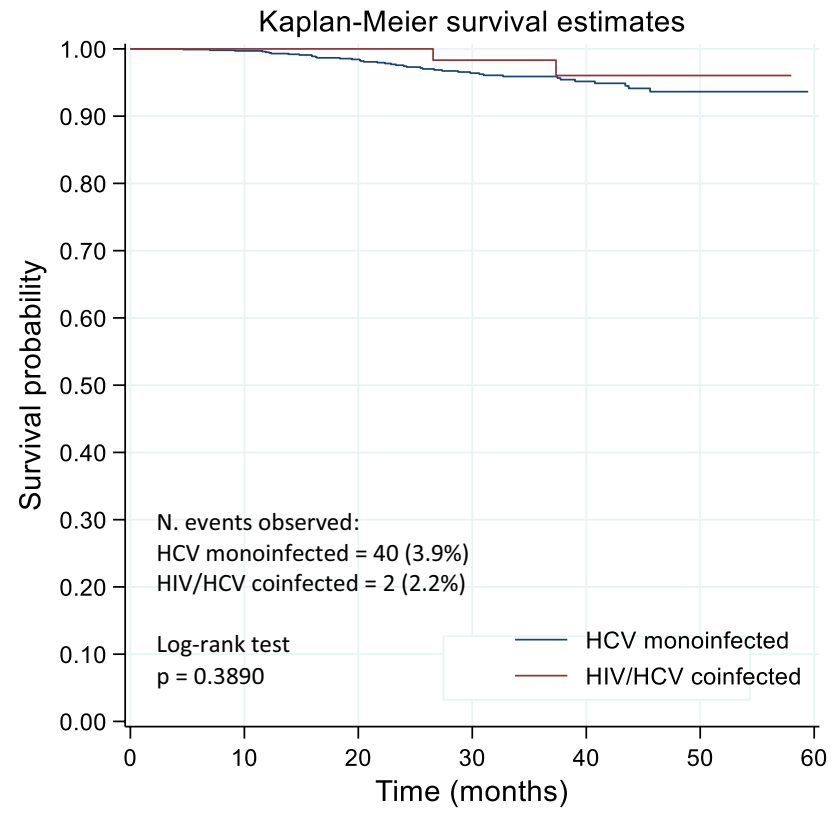

Fig. 1 Kaplan-Meier curves for de novo HCC occurrence by HCV monoinfected and HIV/HCV coinfected groups

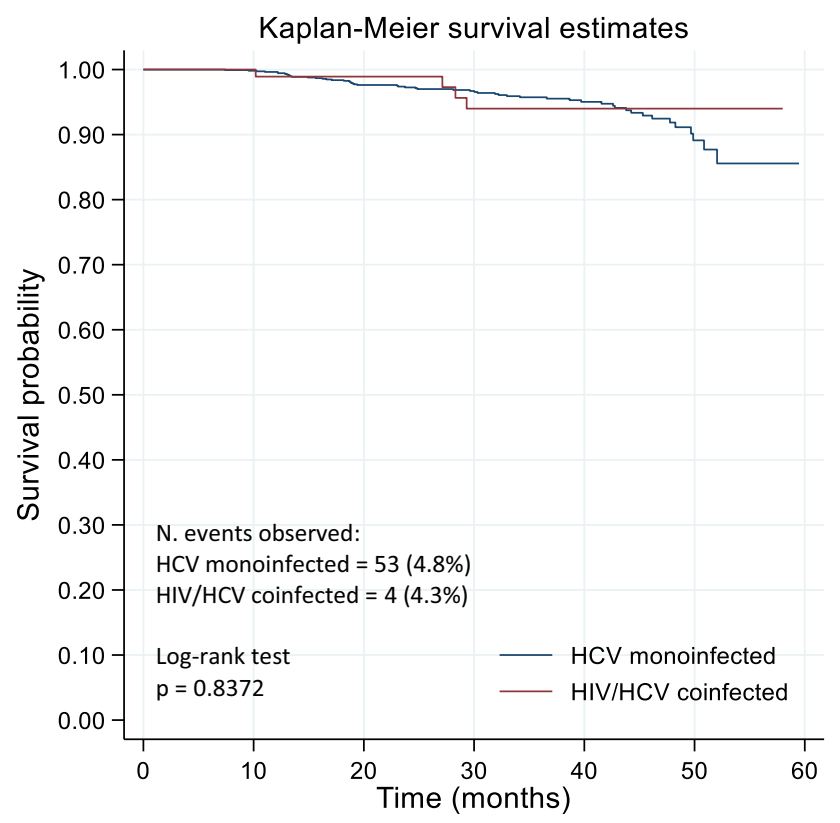

Fig. 2 Kaplan-Meier curves for decompensating event by HCV monoinfected and $\mathrm{HIV} / \mathrm{HCV}$ coinfected groups

was applied taking into account the different background between coinfected and monoinfected groups, to ascertain the impact of HIV coinfection on liver disease outcomes. By Cox regression analyses, using HIV and propensity score as independent covariates, it was confirmed that neither de novo $\mathrm{HCC}$ appearance $(\mathrm{HR}=0.72 ; 95 \%$ CI $0.09-6.10)$ nor hepatic decompensation ( $\mathrm{HR}=0.76$; 95\% CI 0.09-6.21) were influenced by HIV coinfection.

\section{Discussion}

Different countries have built specific registries regarding $\mathrm{HCV}$ and HIV infections. Most of collected data aims to evaluate the dimension of $\mathrm{HCV}$ chronic infection among HIV-infected patients and are mainly focused on the optimization of cART [14-19]. The consecutive nature of the enrolled patients and the involvement of clinical centers of different specialties that deal with monoinfected and coinfected patients (i.e., gastroenterology/hepatology, internal medicine and infectious diseases) all over Italy, independently by the access to the therapy, are important peculiarities of PITER cohort. The results in term of demographic, clinical and virological characteristics of the enrolled patients according to HCV coinfected and monoinfected patients are pretty similar with those of coinfected patients reported by ICONA cohort [15] and different regional cohorts of patients with chronic HCV in Italy (data available in www.progettopiter.it). Moreover, the characteristics of treated patients in the PITER cohort are very similar with overall treated patients in Italy (data available in www.progettopiter.it). For these reasons, PITER is reasonably considered representative of $\mathrm{HCV}$ and HIV/HCV coinfected patients in care in Italy.

Regarding HCV-infected patients enrolled in the PITER cohort, their median age is at least one to two decades older compared to other European cohorts of monoinfected patients which reflects the cohort effect of HCV infected individuals in Italy [20]. The mean age of HIV coinfected patients in care is about one decade younger than monoinfected patients, although older compared to other coinfected European cohorts. This data could be potentially explained by the higher prevalence of injection drug use vs sexual transmission as the main route of HIV transmission in Italy in the past. However, higher mortality rates in HIV coinfected patients, due to the lack of high efficacy of highly active antiretroviral therapy (HAART) in the past, could not be ruled out in explaining this different age pattern of coinfected compared to monoinfected patients in care in Italy.

Regarding HCV genotype distribution, genotype $1 \mathrm{~b}$ is prevalent in monoinfected patients, associated with blood transfusion and unsafe medical procedures (more plausible route of infection in HCV monoinfected patients in Italy), whereas genotype 1a and 3 were dominant in coinfected patients, being mostly intravenous drug use-related (most risk factor in Italian HIV coinfected patients) [21, 22].

The presence of a high proportion of liver cirrhosis in coinfected and monoinfected patients enrolled and subsequently treated for $\mathrm{HCV}$ infection, could reflect the 
Table 3 Variables associated with de novo HCC occurrence. Univariate and multivariate analysis

\begin{tabular}{|c|c|c|}
\hline Baseline factors & Crude HR (95\% CI) & Adjusted HR (95\% CI) \\
\hline HIV infection & $0.54(0.13-2.24)$ & $0.60(0.084 .77)$ \\
\hline Age (increasing years) & $1.06(1.03-1.10)$ & $1.08(1.04-1.13)$ \\
\hline Sex (ref. female) & $2.68(1.28-5.60)$ & $2.76(1.28-5.96)$ \\
\hline $\begin{array}{l}\text { BMI: overweight/obese (ref. under-normal } \\
\text { weight) }\end{array}$ & $1.07(0.58-1.98)$ & \\
\hline Current alcohol use (ref. never) & $1.73(0.70-4.32)$ & \\
\hline Past alcohol use (ref. never) & $2.13(1.09-4.16)$ & \\
\hline ALT (increasing IU/L) & $1.00(0.99-1.00)$ & \\
\hline AST (increasing IU/L) & $1.00(0.99-1.01)$ & \\
\hline Platelets (ref. $>100,000 / \mu \mathrm{L}$ ) & $1.50(0.81-2.79)$ & \\
\hline Albumin (decreasing g/dL) & $4.53(2.24-9.13)$ & $3.94(1.81-8.58)$ \\
\hline Bilirubin (increasing mg/dL) & $1.15(0.94-1.42)$ & \\
\hline INR (increasing unit) & $1.17(0.36-3.81)$ & \\
\hline Genotype (3 vs others) & $1.68(0.75-3.79)$ & $5.05(1.75-14.57)$ \\
\hline Diabetes & $0.95(0.44-2.06)$ & \\
\hline Anti-HBc + & $2.07(1.12-3.84)$ & $1.99(1.01-3.95)$ \\
\hline $\mathrm{HBsAg}+$ & Not estimable ${ }^{\mathrm{b}}$ & \\
\hline Previous interferon & $0.94(0.50-1.79)$ & \\
\hline
\end{tabular}

Statistically significant hazard ratios and related $95 \%$ confidence intervals are reported in bold ${ }^{\mathrm{a}} \mathrm{Cox}$ forward stepwise selection

${ }^{\mathrm{b}}$ Not estimable due to insufficient cases

\begin{tabular}{|c|c|c|}
\hline Baseline factors & Crude HR $(95 \% \mathrm{CI})$ & Adjusted HR (95\% CI) \\
\hline HIV infection & $0.90(0.32-2.49)$ & $0.55(0.07-4.32)$ \\
\hline Age (increasing years) & $1.03(1.00-1.05)$ & $1.03(1.00-1.07)$ \\
\hline Sex (ref. female) & $1.58(0.91-2.77)$ & $2.13(1.06-4.26)$ \\
\hline $\begin{array}{l}\text { BMI: overweight/obese (ref. under-normal } \\
\text { weight) }\end{array}$ & $0.93(0.71-1.20)$ & \\
\hline Current alcohol use (ref. never) & $1.36(0.56-3.29)$ & \\
\hline Past alcohol use (ref. never) & $2.17(1.24-3.82)$ & $1.84(0.97-3.50)$ \\
\hline ALT (increasing IU/L) & $1.00(0.99-1.00)$ & \\
\hline AST (increasing IU/L) & $1.00(0.99-1.01)$ & \\
\hline Platelets (ref. $>100,000 / \mu \mathrm{L}$ ) & $1.95(1.16-3.29)$ & $1.73(0.93-3.20)$ \\
\hline Albumin (decreasing g/dL) & $4.66(2.54-8.56)$ & $3.75(1.89-7.46)$ \\
\hline Bilirubin (increasing mg/dL) & $0.99(0.69-1.42)$ & \\
\hline INR (increasing unit) & $2.11(1.27-3.50)$ & \\
\hline Genotype (3 vs others) & $1.26(0.57-2.79)$ & \\
\hline Diabetes & $1.57(0.88-2.81)$ & \\
\hline Anti-HBc + & $0.47(0.22-1.00)$ & \\
\hline $\mathrm{HBsAg}+$ & $1.03(0.14-7.48)$ & \\
\hline Previous Interferon & $0.74(0.41-1.32)$ & \\
\hline $\mathrm{HCC}$ & $1.85(0.67-5.13)$ & \\
\hline
\end{tabular}

Statistically significant hazard ratios and related $95 \%$ confidence intervals are reported in bold

${ }^{\mathrm{a} C o x}$ forward stepwise selection
Table 4 Variables associated with decompensating event. Univariate and multivariate ${ }^{a}$ analysis prioritization criteria for the access to DAA treatment of patients with advanced liver cirrhosis during 2015-2016 in Italy (www.aifa.gov.it).
Taking into account the younger overall mean age of the coinfected patients and at least one-decade younger age of those with severe liver disease compared to monoinfected 
patients, our data confirm that patients with HIV coinfection progress to advanced liver disease earlier in the natural history of chronic HCV infection compared to HCV monoinfected patients $[2,3]$.

A similar benefit of DAA-based treatment regimens on liver disease severity in both coinfected and monoinfected patients with liver cirrhosis was observed. After successful DAA treatment, preliminary data have shown an improvement in Child-Pugh class (observed in 85\% of coinfected and in $65.9 \%$ of monoinfected patients, with no significant difference between the two groups), suggesting that viral eradication helps liver function recovery in the majority of patients with liver cirrhosis (data not shown). As previously reported, $\mathrm{HCV}$ cured after DAA therapy induce a reduction of the risk of $\mathrm{HCC}$ occurrence compared with non-responders; however, a residual risk still persists even after viral eradication [23-26]. In particular, regarding the HCC occurrence following viral eradication, the cumulative incidence was $2.2 \%$ in coinfected and $3.9 \%$ in monoinfected patients, significantly lower compared to the cumulative incidence of HCC (13.8\%) reported in patients who experienced treatment failure in the PITER cohort [23]. However, careful follow-up is important not only in patients with virological failure or with known risk factors (i.e., decompensation of liver cirrhosis prior to antiviral treatment or a "cured" HCC), but also in patients with F4 fibrosis stage/liver cirrhosis prior to viral eradication. The cumulative incidence reported in this study is similar with previously reported incidence of newly diagnosed HCC at 1 year after exposure to DAA [9, 24-26]. In patients with advanced hepatitis $\mathrm{C}$ receiving DAA, the residual $\mathrm{HCC}$ risk might be lower than that of untreated patients and declines progressively with time after a sustained virological response [26]. Overall, these data indicate a positive role of DAA therapy in reducing the incidence rate of HCC development after viral eradication. In our study, no differences in the occurrence of incident HCC and of decompensating events in short/medium time after viral eradication in coinfected and monoinfected patients have been shown by the survival estimates of these events in both groups. Factors as male sex, older age and lower baseline albumin concentration, which are surrogate markers of advanced liver disease resulted independently associated with de novo HCC appearance. Regarding the incidence of a decompensating event, this study showed that HIV coinfection was not associated with a higher probability of developing liver complications in cirrhotic patients, after viral eradication. The occurrence rate of a decompensating event, following viral eradication, was very similar in coinfected and monoinfected patients $(4.3 \%$ vs $4.8 \%$, respectively) with no differences in the survival estimates in both coinfected and monoinfected populations over the short/medium time of follow-up. Older age, male sex and low baseline albumin concentration were independently associated with decompensation after viral eradication.

Low platelets level was associated to a decompensating event at univariate analysis, though it doesn't result independently associated by stepwise regression analysis, most probably due to not sufficient sample size. In fact, low platelet levels have been previously reported as one of the main predictors of Child-Pugh score deterioration and HCC development in the overall PITER cohort [27] and in accordance with the results of a previous prospective study, signs of portal hypertension can help to stratify the risk of HCC [24].

Regarding the HBV coinfection, the presence of anti$\mathrm{HBc}$ as marker of previous or ongoing HBV infection is significantly higher in coinfected with respect to monoinfected patients ( $45.2 \%$ vs $22.4 \%$, respectively). This data merits double reflection. First, the presence of HBV infection markers in almost half of Italian coinfected population indicates different epidemiological and baseline clinical picture between coinfected and monoinfected population and second, this data could be taken carefully into consideration in the evaluation of clinical outcomes following antiviral therapy. Isolated anti-HBc has been of clinical interest over the past several years, with growing data that suggested it as a serological marker for occult HBV infection with a specific role in the HCC development. Similar to recent data, HBV infection is significantly associated with newly diagnosed $\mathrm{HCC}$ in HCV-infected patients with advanced liver disease [26]. In our study, it was not possible to evaluate the role of HBsAg as predictor markers for HCC development because of the small sample size of patients with HBsAg positivity. Anti-HBc positivity and other $\mathrm{HCV}$ factors associated to $\mathrm{HCC}$ incidence, as genotype 3 , confirm a multistep process in HCC development, not only related to HCV viral replication, once liver cirrhosis is established.

Overall, current data on DAA have shown a lower risk of HCC development; however, they were unable to identify patients at greater risk for HCC occurrence after SVR. Surveillance strategy, likely lifelong, is mandatory in these patients according to general expert opinion [28].

Although the results of short/medium follow-up time following viral eradication have shown no differences in the HCC occurrence among coinfected and monoinfected patients, longer follow-up data in larger sample size are necessary to be evaluated, considering the significant more frequent presence of other cofactors of liver disease progression as presence of HBV coinfection markers and alcohol use after viral eradication in patients with HIV coinfection.

These data could be considered representative of HCV chronically infected patients with liver cirrhosis in Italy and confirm that once a certain severity of liver damage had reached during viral replication liver disease could progress regardless of viral eradication in coinfected and monoinfected patients $[8,29]$. 


\section{Conclusion}

The results of the present study have shown that after successful DAA treatment, patients with advanced liver disease and HIV coinfection have a similar probability of developing liver complications as HCV monoinfected patients. "Curing" HCV is not the ultimate goal in patients with severe liver disease in both coinfected and monoinfected patients. Once liver cirrhosis is established the risk of disease progression is decreased, but still persists regardless of viral eradication. This data has an important relevance also on suggesting active HCV surveillance in patients with liver cirrhosis after viral eradication.

Authors' contributions MGQ: contributed to the concept of the study, data analysis and manuscript writing. LF: performed the statistical analyses; MM, RF, EB, AI, GM, BC, FM, MV, RD, LC, MM, DI, FPR, PB, GV, MP, MGR, FB, TAS, AF, LC, IG, MZ, GP, and GM: contributed to patients' recruitment, enrollment, clinical assessments, data collection, and critically revised the manuscript. LAK: coordinated the study, contributed to the concept of the study, data analysis, and manuscript writing. All authors read and approved the final manuscript.

Funding This study was funded by the Italian Ministry of Health (Grant number RF-2016-02364053).

\section{Compliance with Ethical Standards}

Conflict of interest Maria Giovanna Quaranta, Luigina Ferrigno, Monica Monti, Roberto Filomia, Elisa Biliotti, Andrea Iannone, Guglielmo Migliorino, Barbara Coco, Filomena Morisco, Maria Vinci, Roberta D’Ambrosio, Liliana Chemello, Marco Massari, Donatella Ieluzzi, Francesco Paolo Russo, Pierluigi Blanc, Gabriella Verucchi, Massimo Puoti, Mariagrazia Rumi, Francesco Barbaro, Teresa Antonia Santantonio, Alessandro Federico, Luchino Chessa, Ivan Gentile, Massimo Zuin, Giustino Parruti, Giulia Morsica, Loreta A. Kondili did not receive specific found and declare no conflicts of interest regarding the present study. PITER study has been conducted on a voluntary basis. This study does not refer to specific drug or drug companies and cumulative data on the overall clinical effect after viral eradication are reported within the paper. None of the authors, who are main investigators of clinical centers involved in PITER, declare relationships or interests that could have direct or potential influence or impart bias on the present work.

Ethical approval This study was conducted in accordance with the 1964 Helsinki declaration and its later amendments and the principles of Good Clinical Practice. The study protocol was approved by the Ethics Committee of the Istituto Superiore di Sanità (Italian National Institute of Public Health) and by the local Ethics Committees of each participating clinical center. The patients' data were evaluated anonymously, adopting codes generated by the electronic case-report form. Written informed consent was obtained from all patients for being included in the study.

Open Access This article is licensed under a Creative Commons Attribution 4.0 International License, which permits use, sharing, adaptation, distribution and reproduction in any medium or format, as long as you give appropriate credit to the original author(s) and the source, provide a link to the Creative Commons licence, and indicate if changes were made. The images or other third party material in this article are included in the article's Creative Commons licence, unless indicated otherwise in a credit line to the material. If material is not included in the article's Creative Commons licence and your intended use is not permitted by statutory regulation or exceeds the permitted use, you will need to obtain permission directly from the copyright holder. To view a copy of this licence, visit http://creativecommons.org/licenses/by/4.0/.

\section{References}

1. Platt L, Easterbrook P, Gower E, McDonald B, Sabin K, McGowan C, Yanny I, et al. Prevalence and burden of HCV coinfection in people living with HIV: a global systematic review and meta-analysis. Lancet Infect Dis 2016;16(7):797-808

2. Macías J, Márquez M, Téllez F, Merino D, Jiménez-Aguilar P, López-Cortés LF, Ortega E, et al. Risk of liver decompensation among HIV/hepatitis $\mathrm{C}$ virus-coinfected individuals with advanced fibrosis: implications for the timing of therapy. Clin Infect Dis 2013;57(10):1401-1408

3. Merchante N, Merino E, López-Aldeguer J, Jover F, DelgadoFernández M, Galindo MJ, Ortega E, et al. Increasing incidence of hepatocellular carcinoma in HIV-infected patients in Spain. Clin Infect Dis 2013;56(1):143-150

4. Klein MB, Althoff KN, Jing Y, North American AIDS Cohort Collaboration on Re- search and Design of IeDEA; North American AIDS Cohort Collaboration on Research and Design (NAACCORD) of IeDEA, et al. Risk of end-stage liver disease in HIV-viral hepatitis coinfected persons in North America from the early to modern antiretroviral therapy eras. Clin Infect Dis 2016;63(9):1160-1167

5. Sulkowski MS, Gardiner DF, Rodriguez-Torres M, Reddy KR, Hassanein T, Jacobson I, Lawitz E, et al. Daclatasvir plus sofosbuvir for previously treated or untreated chronic HCV infection. N Engl J Med 2014;370(3):211-221

6. Afdhal N, Reddy KR, Nelson DR, Lawitz E, Gordon SC, Schiff E, Nahass R, et al. Ledipasvir and sofosbuvir for previously treated HCV genotype 1 infection. N Engl J Med 2014;370(16):1483-1493

7. Carrat F, Fontaine H, Dorival C, Simony M, Diallo A, Hezode C, De Ledinghen $\mathrm{V}$, et al. Clinical outcomes in patients with chronic hepatitis $\mathrm{C}$ after direct-acting antiviral treatment: a prospective cohort study. Lancet 2019;393(10179):1453-1464

8. Gentile I, Scotto R, Coppola C, Staiano L, Amoruso DC, De Simone T, Portunato F, et al. Treatment with direct-acting antivirals improves the clinical outcome in patients with HCVrelated decompensated cirrhosis: results from an Italian reallife cohort (Liver Network Activity-LINA cohort). Hepatol Int 2019;13(1):66-74

9. Calvaruso V, Cabibbo G, Cacciola I, Petta S, Madonia S, Bellia A, Tinè $\mathrm{F}$, et al. Incidence of Hepatocellular Carcinoma in Patients With HCV-Associated Cirrhosis Treated With Direct-Acting Antiviral Agents. Gastroenterology 2018;155(2):411-421

10. ANRS collaborative study group on hepatocellular carcinoma (ANRS CO22 HEPATHER, CO12 CirVir and CO23 CUPILT cohorts). Lack of evidence of an effect of direct-acting antivirals on the recurrence of hepatocellular carcinoma: Data from three ANRS cohorts. J Hepatol 2016;65(4):734-740

11. Meissner EG. Update in HIV/HCV Co-Infection in the Direct Acting Antiviral Era. Curr Opin Gastroenterol 2017;33(3):120-127

12. Kondili LA, Vella S, PITER Collaborating Group. PITER: An ongoing nationwide study on the real-life impact of direct acting antiviral based treatment for chronic hepatitis C in Italy. Dig Liver Dis 2015;47(9):741-743 
13. Ziol M, Handra-Luca A, Kettaneh A, Christidis C, Mal F, Kazemi $\mathrm{F}$, de Lédinghen $\mathrm{V}$, et al. Noninvasive assessment of liver fibrosis by measurement of stiffness in patients with chronic hepatitis $\mathrm{C}$. Hepatology 2005;41(1):48-54

14. Piroth L, Wittkop L, Lacombe K, Rosenthal E, Gilbert C, Miailhes $\mathrm{P}$, Carrieri $\mathrm{P}$, et al. Efficacy and safety of direct-acting antiviral regimens in HIV/HCV-co-infected patients - French ANRS CO13 HEPAVIH cohort. J Hepatol 2017;67(1):23-31

15. d'Arminio Monforte A, Cozzi-Lepri A, Ceccherini-Silberstein F, De Luca A, Lo Caputo S, Castagna A, Mussini C, et al. Access and response to direct antiviral agents (DAA) in HIV-HCV coinfected patients in Italy: Data from the Icona cohort. PLoS One. 2017;12(5):e0177402

16. Corma-Gómez A, Morano L, Téllez F, Rivero-Juárez A, Real LM, Alados JC, Ríos-Villegas MJ, et al. HIV infection does not increase the risk of liver complications in hepatitis $\mathrm{C}$ virus-infected patient with advanced fibrosis, after sustained virological response with direct-acting antivirals. AIDS 2019;33(7):1167-1174

17. Ingiliz P, Christensen S, Kimhofer T, Hueppe D, Lutz T, Schewe $\mathrm{K}$, Busch $\mathrm{H}$, et al. Sofosbuvir and Ledipasvir for 8 Weeks for the Treatment of Chronic Hepatitis C Virus (HCV) Infection in HCV-Monoinfected and HIV-HCV-Coinfected Individuals: results From the German Hepatitis C Cohort (GECCO-01). Clin Infect Dis 2016;63(10):1320-1324

18. Janjua NZ, Kuo M, Chong M, Yu A, Alvarez M, Cook D, Armour $\mathrm{R}$, et al. Assessing Hepatitis C Burden and Treatment Effectiveness through the British Columbia Hepatitis Testers Cohort (BCHTC): design and Characteristics of Linked and Unlinked Participants. PLoS ONE 2016;11(3):e0150176

19. Gordon SC, Lamerato LE, Rupp LB, Holmberg SD, Moorman AC, Spradling PR, Teshale E, et al. Prevalence of cirrhosis in hepatitis $\mathrm{C}$ patients in the Chronic Hepatitis Cohort Study (CHeCS): a retrospective and prospective observational study. Am J Gastroenterol 2015;110(8):1169-1177

20. Guadagnino V, Stroffolini T, Rapicetta M, Costantino A, Kondili LA, Menniti-Ippolito F, Caroleo B, et al. Prevalence, risk factors, and genotype distribution of hepatitis $C$ virus infection in the general population: a community-based survey in southern Italy. Hepatology 1997;26(4):1006-1011

21. Wiessing L, Ferri M, Grady B, Kantzanou M, Sperle I, Cullen KJ, Hatzakis A, Prins M, Vickerman P, Lazarus JV, Hope VD, Matheï C, EMCDDA DRID group. Hepatitis C virus infection epidemiology among people who inject drugs in Europe: a systematic review of data for scaling up treatment and prevention. PLoS One 2014;9(7):e103345 https://doi.org/10.1371/journal.pone.0103345.
22. Roffi L, Ricci A, Ogliari C, Scalori A, Minola E, Colloredo G, et al. HCV genotypes in Northern Italy: a survey of 1368 histologically proven chronic hepatitis C patients. J Hepatol 1998;29:701-706

23. Kondili LA, Gaeta GB, Brunetto MR, Di Leo A, Iannone A, Santantonio TA, Zuin M, et al. Incidence of DAA failure and the clinical impact of retreatment in real-life patients treated in the advanced stage of liver disease: interim evaluations from the PITER network. PLoS One 2017;12(10):e0185728 https://doi. org/10.1371/journal.pone.0185728.

24. Lleo A, Aglitti A, Aghemo A, Maisonneuve P, Bruno S, Persico $\mathrm{M}$, collaborators. Predictors of hepatocellular carcinoma in HCV cirrhotic patients treated with direct acting antivirals. Dig Liver Dis 2019;51:310-317

25. Ide T, Koga H, Nakano M, Hashimoto S, Yatsuhashi H, Higuchi $\mathrm{N}$, et al. Direct-acting antiviral agents do not increase the incidence of hepatocellular carcinoma development: a prospective, multicenter study. Hepatol Int 2019;13(3):293-301

26. Romano A, Angeli P, Piovesan S, Noventa F, Anastassopoulos G, Chemello L, Cavalletto L, Gambato M, Russo FP, Burra P, Vincenzi V, Scotton PG, Panese S, Tempesta D, Bertin T, Carrara M, Carlotto A, Capra F, Carolo G, Scroccaro G, Alberti A. Newly diagnosed hepatocellular carcinoma in patients with advanced hepatitis C treated with DAAs: a prospective population study. J Hepatol 2018;69(2):345-352

27. Kondili LA, Quaranta MG, Rosato S, Weimer LE, D'Angelo F, Coppola C, et al. Predictive Factors for Liver Disease Progression Following the Direct Acting Antivirals Induced Sustained Virological Response: data from the Italian Platform for the Study of Viral Hepatitis Therapies (PITER) Cohort. Hepatology 2018;68(S1):889A-890A

28. Galati G, Muley M, Viganò M, Iavarone M, Vitale A, Dell'Unto C, et al. Occurrence of hepatocellular carcinoma after direct-acting antiviral therapy for hepatitis $\mathrm{C}$ virus infection: literature review and risk analysis. Expert Opin Drug Saf 2019;18(7):603-610

29. van der Meer AJ, Feld JJ, Hofer H, Almasio PL, Calvaruso V, Fernández-Rodríguez CM, Aleman S, Ganne-Carrié N, et al. Risk of cirrhosis-related complications in patients with advanced fibrosis following hepatitis C virus eradication. J Hepatol 2017;66(3):485-493

Publisher's Note Springer Nature remains neutral with regard to jurisdictional claims in published maps and institutional affiliations.

\section{Affiliations}

\section{Maria Giovanna Quaranta ${ }^{1}$. Luigina Ferrigno ${ }^{1} \cdot$ Monica Monti $^{2} \cdot$ Roberto Filomia $^{3}$. Elisa Biliotti ${ }^{4} \cdot$ Andrea lannone $^{5}$. Guglielmo Migliorino $^{6} \cdot$ Barbara Coco $^{7} \cdot$ Filomena Morisco $^{8} \cdot$ Maria Vinci $^{9} \cdot$ Roberta D'Ambrosio $^{10}$. Liliana Chemello ${ }^{11}$ - Marco Massari ${ }^{12}$. Donatella leluzzi ${ }^{13}$. Francesco Paolo Russo ${ }^{14}$. Pierluigi Blanc ${ }^{15}$. Gabriella Verucchi ${ }^{16}$. Massimo Puoti ${ }^{17}$. Maria Grazia Rumi ${ }^{18}$. Francesco Barbaro ${ }^{19}$. Teresa Antonia Santantonio ${ }^{20}$. Alessandro Federico ${ }^{21}$. Luchino Chessa ${ }^{22}$ - Ivan Gentile ${ }^{23}$. Massimo Zuin ${ }^{24}$. Giustino Parruti ${ }^{25}$. Giulia Morsica ${ }^{26}$. Loreta A. Kondili ${ }^{1}$ - on behalf of PITER Collaborating Group}

Maria Giovanna Quaranta

mariagiovanna.quaranta@iss.it

Luigina Ferrigno

luigina.ferrigno@iss.it

Monica Monti

monica.monti@unifi.it
Roberto Filomia

robertofilomia@hotmail.it

Elisa Biliotti

elisabiliotti@yahoo.it

Andrea Iannone

ianan@hotmail.it 
Guglielmo Migliorino

g.migliorino@asst-monza.it

Barbara Coco

b.coco@ao-pisa.toscana.it

Filomena Morisco

filomena.morisco@unina.it

Maria Vinci

maria.vinci@ospedaleniguarda.it

Roberta D'Ambrosio

roberta.dambrosio@policlinico.mi.it

Liliana Chemello

liliana.chemello@unipd.it

Marco Massari

massari.marco@ausl.re.it

Donatella Ieluzzi

donatella.ieluzzi@ospedaleuniverona.it

Francesco Paolo Russo

francescopaolo.russo@unipd.it

Pierluigi Blanc

pierluigi.blanc@uslcentro.toscana.it

Gabriella Verucchi

gabriella.verucchi@unibo.it

Massimo Puoti

massimo.puoti@ospedaleniguarda.it

Maria Grazia Rumi

mariagrazia.rumi@unimi.it

Francesco Barbaro

francesco.barbaro@aopd.veneto.it

Teresa Antonia Santantonio

t.santantonio@unifg.it

Alessandro Federico

alessandro.federico@unicampania.it

Luchino Chessa

luchinochessa@unica.it

Ivan Gentile

ivan.gentile@unina.it

Massimo Zuin

massimo.zuin@unimi.it

Giustino Parruti

parruti@tin.it

Giulia Morsica

morsica.giulia@hsr.it

on behalf of PITER Collaborating Group

http://www.progettopiter.it

1 Center for Global Health, Istituto Superiore di Sanità, Rome, Italy

2 Center for Systemic Manifestations of Hepatitis Viruses (MaSVE), Department of Experimental and Clinical Medicine, University of Florence, Florence, Italy
Division of Clinical and Molecular Hepatology, University Hospital of Messina, Messina, Italy

4 Department of Clinical Medicine, Policlinico Umberto I, Sapienza University of Rome, Rome, Italy

5 Department of Emergency and Organ Transplantation, Gastroenterology Unit, University of Bari, Bari, Italy

6 Division of Infectious Diseases, San Gerardo Hospital, Monza, Italy

7 Hepatology and Liver Physiopathology Laboratory and Internal Medicine, Department of Clinical and Experimental Medicine, University Hospital of Pisa, Pisa, Italy

8 Gastroenterology and Hepatology Unit, Federico II University Hospital, Naples, Italy

9 Department of Hepatology and Gastroenterology, Niguarda Hospital, Milan, Italy

10 Gastroenterology and Hepatology Unit, Fondazione IRCCS Ca' Granda Ospedale Maggiore Policlinico, Milan, Italy

11 Department of Medicine, University Hospital of Padua, Padua, Italy

12 Infectious Diseases, Azienda Unità Sanitaria Locale, IRCCS di Reggio Emilia, Reggio Emilia, Italy

13 USD Liver Unit, University Hospital of Verona, Verona, Italy

14 Gastroenterology Unit, Department of Surgery, Oncology and Gastroenterology, University of Padua, Padua, Italy

15 Infectious Disease Unit, Santa Maria Annunziata Hospital, Florence, Italy

16 Department of Medical and Surgical Sciences, Infectious Disease Unit, University Hospital S.Orsola-Malpighi, Bologna, Italy

17 Department of Infectious Disease, Niguarda Hospital, Milan, Italy

18 Hepatology Unit, San Giuseppe Hospital, University of Milan, Milan, Italy

19 Infectious and Tropical Diseases Unit, Azienda Ospedaliera di Padova, Padua, Italy

20 Infectious Diseases, Ospedali Riuniti, Foggia, Italy

21 Department of Hepato-Gastroenterology, University of Campania "Luigi Vanvitelli”, Naples, Italy

22 Liver Unit, University Hospital, Monserrato, Cagliari, Italy

23 Infectious Disease Unit, Federico II University Hospital, Naples, Italy

24 Gastroenterology and Hepatology Unit, San Paolo Hospital, University of Milan, Milan, Italy

25 Infectious Disease Unit, Spirito Santo General Hospital, Pescara, Italy

26 Department of Infectious Diseases, San Raffaele Hospital, Milan, Italy 